\title{
Erratum to: Removal mechanism of low-concentration Cr (VI) in a submerged membrane bioreactor activated sludge system
}

\author{
Siqing Xia ${ }^{1}$ - Lijie Zhou ${ }^{1,2}$ - Zhiqiang Zhang ${ }^{1,3}$ - Slawomir W. Hermanowicz ${ }^{2,4}$
}

Published online: 15 May 2015

(C) Springer-Verlag Berlin Heidelberg 2015

Erratum to: Appl Microbiol Biotechnol (2015)

DOI 10.1007/s00253-015-6590-5

The original version of this article inadvertently contains mistake. Equations (1) and (3) were incorrectly presented. The correct equations are given below:

Equation (1)

$$
(\mathrm{SOH})_{2}+2 \mathrm{H}^{+}+\mathrm{CrO}_{4}^{2-} \rightarrow \begin{aligned}
& \mathrm{SOH}_{2}^{+} \\
& \mathrm{SOH}_{2}^{+}>\mathrm{CrO}_{4}^{2-}
\end{aligned}
$$

Equation (3)

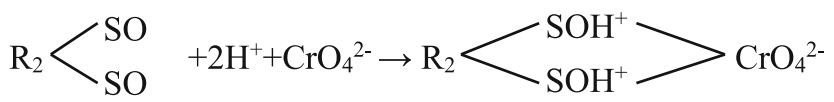

The online version of the original article can be found at http://dx.doi.org/ 10.1007/s00253-015-6590-5.

Lijie Zhou

pakerzhou@gmail.com

1 State Key Laboratory of Pollution Control and Resource Reuse, College of Environmental Science and Engineering, Tongji University, Shanghai 200092, China

2 Department of Civil and Environmental Engineering, University of California, Berkeley, CA 94720, USA

3 Key Laboratory of Yangtze River Water Environment, Ministry of Education, College of Environmental Science and Engineering, Tongji University, Shanghai 200092, China

4 National High-end Foreign Expert Program, Tongji University, Shanghai 200092, China 